\title{
Childbirth and pelvic floor disorders
}

\section{Rebecca G. Rogers ${ }^{1}$}

Published online: 28 February 2020

(C) The International Urogynecological Association 2020

In this special issue of the International Urogynecology Journal, we focus on research from around the world on the impact of childbirth on pelvic floor function. Over the past two decades, the mechanisms underlying pelvic floor dysfunction following birth are better defined, and we better understand how to recognize, avoid, and treat severe perineal lacerations following birth. Less well defined is how to prevent subsequent incontinence and prolapse, other than the avoidance of vaginal birth. Some evidence for the impact of vaginal birth on pelvic floor dysfunction is contradictory. For example, although we know that vaginal birth is associated with a greater impact on the levator ani [1], for women who have sustained a prior anal sphincter injury, a subsequent vaginal birth was not associated with worsening of bowel symptoms or sphincter integrity [2]. Why are some women severely affected by a single uncomplicated vaginal birth and others not affected after five similar births? We are still discovering underlying mechanisms that may help us to individualize birth plans. For example, ligamentous laxity may be associated with increased risk of obstetrical anal sphincter laceration with a sensitivity of $75 \%$ [3]. Nonetheless, much is to be discovered about the causes, identification, prevention, and treatment of childbirth-associated pelvic floor trauma.

In a letter to our journal, Dr. Braga, one of our Swiss colleagues, enjoins us to apply evidence-based practice to deliveries. She urges us to accurately identify anal sphincter lacerations at the time of delivery, use mediolateral episiotomy when episiotomy is necessary, and to consider support of the fetal head during delivery [4]. Dr. Fairchild in the USA defines normal recovery following birth by comparing women delivered by cesarean versus vaginal birth. A combination of low posterior vaginal wall support, decreased pelvic floor muscle

Rebecca G. Rogers

Rebecca.rogers@austin.utexas.edu

1 Department of Women's Health, Dell Medical School, University of Texas, 1301 W 38th Street Suite 705, Austin, TX 78705, USA strength, and imaging consistent with levator ani tear after birth may predict poorer recovery of pelvic floor function following birth. Prolonged recovery was greatest among women with high-risk delivery events such as operative vaginal delivery, prolonged second stage, episiotomy, and anal sphincter laceration [5].

Dr. Schwarzman, one of our Israeli colleagues, analyzed a large cohort of women who delivered vaginally or by cesarean section between 1991 and 2017. The cesarean delivery group was further dichotomized into those whose cesarean was complicated by an abnormal second stage of labor and those who underwent cesarean in the first stage of labor. They found a relatively low overall incidence of hospitalization for a pelvic floor disorder diagnosis of $0.7 \%$, with the highest incidence among women who underwent vaginal birth. Interestingly, cesarean delivery was only protective among women who were delivered by cesarean in the first stage of labor [6].

Whether or not anti-incontinence surgery should be performed prior to a women's completion of childbearing was investigated by Dr. Dyrkorn from Norway. He conducted a case-control study to compare the impact of childbirth after midurethral sling surgery among women with at least 10 years of follow-up after their midurethral sling. Stress urinary incontinence recurrence following midurethral sling was not associated with childbirth or mode of delivery. Nonetheless, women with more than one delivery after their sling surgery were less likely to have stress incontinence cure [7].

In the following pages, you will find more research on the impact of childbirth on pelvic floor dysfunction. This research comes from your colleagues who are grappling with dilemmas that urogynecologists face everywhere. How do we best prevent, treat, and identify pelvic floor dysfunction and individualize the care of women giving birth so that they have the lowest risk of harm? Some of the answers are to found here.

\section{Compliance with ethical standards}

Conflicts of interest R.G.R. receives royalties from Uptodate, and a stipend and travel from IUGA, ACOG, and ABOG. 


\section{References}

1. De Araujo CC, Coelho SA, Stahlschmidt P, Juliato CRT. Does vaginal delivery cause more damage to the pelvic floor than cesarean section as determined by 3D ultrasound evaluation? A systematic review. Int Urogynecol J. 2018;29(5):639-45.

2. Jordan PA, Naidu M, Thakar R, Sultan AH. Effect of subsequent vaginal delivery of bowel symptoms and anorectal function in women who sustained a previous obstetric anal sphincter injury. Int Urogynecol J. 2018;29(11):1579-88.

3. Gachon B, Desgranges M, Fradet L, Decatoire A, Poireault F, Pierre $\mathrm{F}$, et al. Is increased peripheral ligamentous laxity in term pregnant women associated with obstetric anal sphincter injury? Int Urogynecol J. 2018;29(11):1589-95.

4. Braga A, Caccia G, Papadia A, Torella M. Atraumatic childbirth: is it a utopia? Int Urogynecol J. 2019. https://doi.org/10.1007/s00192019-04205-3.
5. Fairchild PS, Low LK, Kowalk KM, Kolenic GE, DeLancey JO, Fenner DE. Defining "normal recovery" of pelvic floor function and appearance in a high-risk vaginal delivery cohort. Int Urogynecol J. 2019. https://doi.org/10.1007/s00192-019-04152-z.

6. Schwarzman P, Paz Levy D, Walfisch A, Sergienko R, Bernstein EH, Sheiner E. Pelvic floor disorders following different delivery modes - a population-based cohort analysis. Int Urogynecol J. 2019. https://doi.org/10.1007/s00192-019-04151-0.

7. Dyrkorn OA, Staff AC, Kulseng-Hanssen S, Schiotz HA, Svenningsen R. Childbirth after mid-urethral sling surgery: effects on long-term success and complications. Int Urogynecol J. 2019. https://doi.org/10.1007/s00192-019-04067-9.

Publisher's note Springer Nature remains neutral with regard to jurisdictional claims in published maps and institutional affiliations. 